\title{
Monitoring of Temporal and Spatial Changes of Land Use and Land Cover in Metropolitan Regions through Remote Sensing and GIS
}

\author{
Mohamed Ali Mohamed \\ Lab. of Geomorphology, Soil Geography and Quaternary Research, Department of Geography, Humboldt University of Berlin, \\ Berlin, Germany \\ Email: mohamed.ali.mohamed@geo.hu-berlin.de
}

How to cite this paper: Mohamed, M.A. (2017) Monitoring of Temporal and Spatial Changes of Land Use and Land Cover in Metropolitan Regions through Remote Sensing and GIS. Natural Resources, 8, 353-369.

https://doi.org/10.4236/nr.2017.85022

Received: March 14, 2017

Accepted: May 21, 2017

Published: May 26, 2017

Copyright $\odot 2017$ by author and Scientific Research Publishing Inc. This work is licensed under the Creative Commons Attribution International License (CC BY 4.0).

http://creativecommons.org/licenses/by/4.0/

\begin{abstract}
The use of remote sensing techniques and subsequent analysis by means of geographical information system (GIS) offers an effective method for monitoring temporal and spatial changes of landscapes. This work studies the urbanization processes and associated threats to natural ecosystems and resources in the metropolitan areas of Berlin and Erlangen-Fürth-NürnbergSchwabach (EFNS). To compute the land use/cover (LULC) of the study areas, a supervised classification of "maximum likelihood" using Landsat data for the years of 1972, 1985, 1998, 2003, and 2015 is used. Results show that the built-up area is the dominant land use in both regions throughout the study period. This land use has increased at the expense of green and open areas in EFNS and at the expense of agricultural land in Berlin. Likewise, 5\% of forest in EFNS is replaced with urban infrastructure. However, the amount of forest in Berlin increased by $3 \%$. While EFNS experienced relatively big changes in its water bodies from 1972 to 1985, changes in water bodies in Berlin were rather slight during the last 40 years. The overall accuracy of our remotely sensed LULC maps was between $88 \%$ and $94 \%$ in Berlin and between $85.87 \%$ and $87.4 \%$ for EFNS. The combination of remote sensing and GIS appears to be an indispensable tool for monitoring changes in LULC in urban areas and help improving LU planning to avoid environmental and ecological problems.
\end{abstract}

\section{Keywords}

Land Use Change, Change Detection, Remote Sensing, GIS, Metropolis City, Metropolitan Region

\section{Introduction}

LULC change is a major issue of global environment change. In addition, LULC 
mapping is an essential component where required parameters are integrated on the requirement basis to drive various developmental indexes for land and water resource. LU refers to man's activities and the varied uses carried on, such as natural vegetation, water bodies, rock, soil and artificial covers. Land cover (LC) is defined as the assemblage of biotic and abiotic components on the earth's surface is one of the most crucial properties of the earth system. LC is that which covers the surface of the earth and land use (LU) describes how the LC is modified. LC includes water, snow, grassland, forest, and bare soil. LU includes agricultural land, built up area, recreation area, wildlife management area etc. The LC reflects the biophysical state of the earth's surface and immediate subsurface, thus embracing the soil material, vegetation and water. LU refers to man's activities on land, which are directly related to the land. LULC are dynamic. Changes may involve the nature or intensity of change but may also include spatial and temporal aspects [1]. LULC changes directly and indirectly involve the modification of natural habitats and their impact on the ecology of the area.

Urban LC types and their spatial distributions are fundamental data required for a wide range of studies in the physical and social sciences, as well as by municipalities for land planning purposes [2]. Remote sensing technology and GIS provide efficient methods for analyzing the LU issues and including tools for planning and modeling [1]. In this respect, multitemporal remote sensing and GIS data offer a great possibility for the documentation and the detection of LU changes at the regional level [3]. Understanding the LU drivers in the past, helps us to improve the management of current GIS tools and modelling the future. And by understanding these drivers, one could develop plans for multiple uses of natural resources and nature conservation [1]. In this context, the advantage of remote sensing data is that collecting data are much faster and efficient in contrast with terrestrial surveys and field works. The resulting information can be used as an important data basis for decision-making at different levels of LU planning. Linking remote sensing and GIS data with existing cartographic as well as terrestrial survey offers the possibility of spatial analysis to forecasts the future developments.

Visible and shortwave infrared (SWIR) bands of Landsat Multispectral Scanner (MSS) and Thematic Mapper (TM) data have been extensively used for forestry and agricultural LC analysis since the Landsat program began in 1972 [2]. Urban LC analysis has also made extensive use of the MSS and TM scanners. However, the relatively low spatial resolution of the MSS $(79 \mathrm{~m})$ and TM (28.5 m) data only allows classification of LC to level 1 - 2 of the Anderson system [2] [4]. Data collected by the MSS and TM will continue to be used as a historical global database. For example, to depict the history of past spatial and temporal changes of soil salinity in China, archive remote sensing images were used (MSS and TM Data). Landsat was chosen as the major source and longest continuously acquired collection of space-based remote sensing data [5]. However, the basic technique is applicable to any remotely sensed data that could improve the accuracy of spectral and/or spatial resolution of those data. 
The majority of studies relied on remotely sensed information in order to classify LC types. Geological and biological applications have also used band ratio techniques to accentuate the spectral features of specific surficial materials, biomass, and vegetation health [2]. LC classification of urban areas has been problematic due to the heterogeneity and small spatial size of the surficial materials, which leads to significant subpixel mixing [2] [6] [7]. This problem becomes a problem by discrimination when multiple classes are required. Significant improvements in the accuracy of LC classification in urban areas have been achieved using a variety of sophisticated approaches including: 1) the use of neural networks; 2) fuzzy classification and 3) image texture analysis [2] [6].

Yet another successful technique for improving classification accuracy is incorporating post-classification in a supervised mode classification (expert system) [2] [8] [9] [10]. Harris \& Ventura (1995) used zoning and housing density information to perform a post-classification (maximum likelihood) with TM data for the region of Beaver Dam, Wisconsin area [2]. Vogelmann et al. (1998) also used TM data to incorporate vegetation indices together with several ancillary datasets. Later were the indices used to monitor the LC change of about 30 million-hectare in the eastern United States [11]. Greenberg and Bradley (1997) reported population and road density information with TM data in Seattle, WA area [12]. Stuckens et al. (2000) produced a LC classification of the Minneapolis-St. Paul, MN urban area using TM data with ancillary LU and wetland inventory information [13].

The present work applies a supervised classification (expert system) approach for the classification of the urban LC in metropolitan regions. The main purpose of the present study is to examine the possibilities of using remote sensing data to analyze the nature and extent the LULC changes in the metropolitan city of Berlin and the metropolitan region of Nürnberg-Fürth-Erlangen-Schwabach in the past 40 years. The objective of this research would be identifying the main forces behind these changes. This study attempts to establish the relationships between the ground truth and the remotely sensed images, maps and reports.

\section{Study Areas}

This study has chosen the metropolitan city of Berlin and the metropolitan region of Nürnberg-Fürth-Erlangen-Schwabach as the study areas. The metropolitan city of Berlin presents the central area of the European metropolitan region of Berlin Brandenburg. Thus, in its function as federal capital and metropolitan center of the region, Berlin is surrounded by a dense suburban space with a partial rural character [14]. The study area of Berlin located in northeastern Germany on the Spree River. Its borders range from $52^{\circ} 25^{\prime} 10.79^{\prime \prime} \mathrm{N}$ to $52^{\circ} 26^{\prime} 07.31^{\prime \prime} \mathrm{N}$ and $13^{\circ} 25^{\prime} 08.52^{\prime \prime E}$ to $13^{\circ} 28^{\prime} 46.10^{\prime \prime E}$. Its covers $891.75 \mathrm{~km}^{2}$ (Figure 1). Berlin with a population of about 3.5 million inhabitants is the largest city in Germany. Large city center areas of Berlin have the highest population densities in Germany (population density 3800 inhabitant $/ \mathrm{km}^{2}$ ). The city consists of twelve districts. In addition to the rivers Spree and Havel, there are smaller rivers in the 


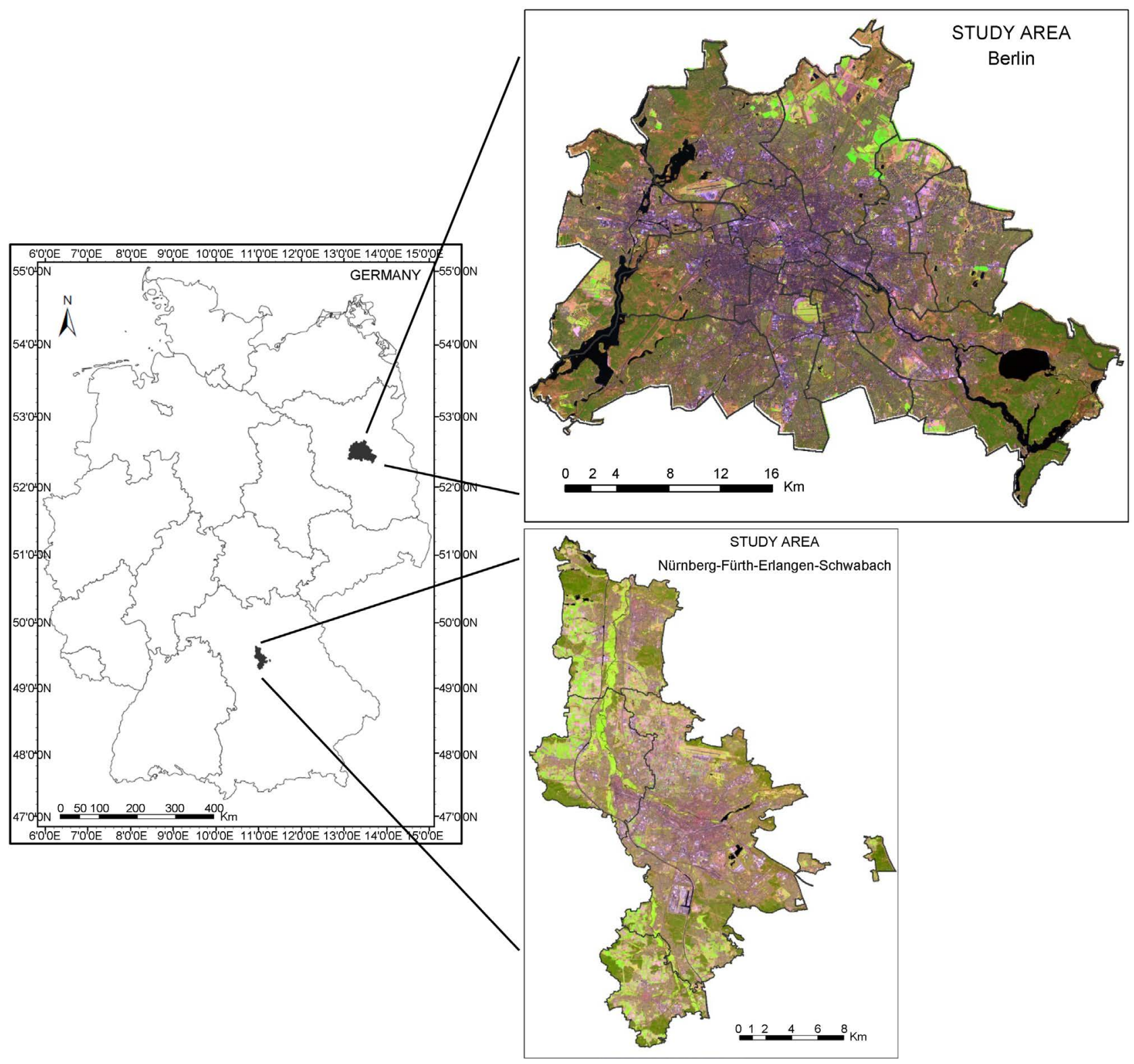

Figure 1. Location map of the study areas and false colors composite of Landsat TM image (band 543 as RGB).

city as well as numerous lakes and forests. Due to its location in the North European Plain, Berlin is influenced by a temperate seasonal climate. Around one third of the city's area is composed of forests, parks, gardens, rivers and lakes. Berlin is surrounded by the state of Brandenburg. The city is located in the temperate climate zone with humid continental climate. The average annual temperature in Berlin-Dahlem is $9.5^{\circ} \mathrm{C}$ and the average annual precipitation is 591 $\mathrm{mm}$. The warmest months are July and August, with average temperatures of $19.1^{\circ} \mathrm{C}-18.2^{\circ} \mathrm{C}$ while the coldest month is January, with average temperature of $0.6^{\circ} \mathrm{C}$. Berlin's built-up area creates a microclimate, where heat is stored by the city's buildings. The temperatures can be up to $4^{\circ} \mathrm{C}$ higher in the city than in the surrounding areas.

The Metropolitan region of Nürnberg-Fürth-Erlangen-Schwabach represents 
the metropolitan center of the European Metropolitan Region of Nürnberg. This region is located in the southern part of the Federal state of Bavaria in the south east of the Federal Republic of Germany. It belongs to the Middle Franconian basin (Figure 1) and extends between $49^{\circ} 24^{\prime} 49.69^{\prime \prime} \mathrm{N}$ to $49^{\circ} 29^{\prime} 42.53^{\prime \prime} \mathrm{N}$ and $10^{\circ} 56^{\prime} 09.14^{\prime \prime} \mathrm{E}$ to $11^{\circ} 01^{\prime} 27.50^{\prime \prime} \mathrm{E}$ and with an area of $367.46 \mathrm{~km}^{2}$, including the administrative boundaries of the cities of Erlangen, Nürnburg, Fürth and Schwabach. The region has a humid cool transitional climate, influenced by its inland position and higher altitude, which creates seasonal differences reminiscent of continental climates. However, the winter seasons are somewhat milder. The monthly average temperature varies between $-1.4^{\circ} \mathrm{C}$ in January and $18^{\circ} \mathrm{C}$ in August. The peak temperature of $35^{\circ} \mathrm{C}$ is reached on some days in summer. Winter seasons are diverse, with either mild or cold weather: the average temperature is around $-3^{\circ} \mathrm{C}$ to $4^{\circ} \mathrm{C}$, while summers are generally warm, mostly around $13^{\circ} \mathrm{C}$. Precipitation is evenly spread throughout the year, although February and April tend to be a drier whereas July tends to have more rainfall. The average annual precipitation in this region is $644 \mathrm{~mm}$ (Nürnberg Station).

\section{Materials and Methods}

\subsection{Data Source}

To depict the history of past spatial and temporal changes of LULC in study areas, archive remote sensing images has been chosen. To achieve the results, several multispectral Landsat data such as Landsat 4 (MSS), Landsat 5 (TM) and 8 (OLI) were downloaded for Berlin (path 193, row 23) and Nürnberg-FürthErlangen-Schwabach (path 193, row 26). Images acquired in five specific years (1972, 1985, 1998, 2003 and 2015). Table 1 shows the details on the mentioned Landsat data. TM and MSS are optical sensors which have 7, 11 and 4 multispectral bands between visible and infrared spectrum. In addition, land cover maps, topographic maps and reports (statistics) has been used in order to improve the overall accuracy of the remote sensing classifications (Table 2 and Table 3).

\subsection{Data Preprocessing}

All the images used in this study have been systematically corrected. Geometric corrections were performed by using ground control points (GCPs) from the digital topographic maps, LU maps and GPS control points. Identical control points were used for all five scenes to obtain a good geometric accordance. This is very important for change analysis based on Geodata. The goal of image enhancement is to improve the visual interpretability of an image by increasing the

Table 1. Spatial data sources of Landsat.

\begin{tabular}{ccc}
\hline Data source (Sensor) & Month of Observation & Spatial Resolution $(\mathrm{m})$ \\
\hline LANDSAT4 (MSS) & August 1972 & 60 \\
LANDSAT5 (TM) & May 1985, April 1998 and June 2003 & 30 \\
LANDSAT8 (OLI) & May 2015 & 30 \\
\hline
\end{tabular}


Table 2. Maps and documents for the metropolitan city of Berlin.

\begin{tabular}{ccc}
\hline Map & Scale & Year \\
\hline Land use plan & $1: 35,000$ & $1965,1984,1994$ \\
& $1: 50,000$ & $1998,2004,2009,2015$ \\
Soil map & $1: 50,000$ & $1990,1998,2005,2013$ \\
Soil evaluation map & $1: 50,000$ & $2001,2005,2010$ \\
Topographic map & $1: 5000$ & $2001,2003,2006,2008,2010,2012,2014$ \\
General map Berlin & $1: 50,000$ & 2015 \\
Green and open spaces map & $1: 50,000$ & $1990,2000,2001,2005,2010$ \\
\hline
\end{tabular}

Table 3. Maps and documents for the metropolitan region of Nürnberg-Fürth-ErlangenSchwabach.

\begin{tabular}{|c|c|c|c|}
\hline Maps and data base & Scale & Year & Study Area \\
\hline \multirow{6}{*}{ Land use plan } & $1: 10,000$ & 1970, 2006, 2015 & Fürth \\
\hline & $1: 5000$ & 1985 & \multirow{2}{*}{ Schwabach } \\
\hline & $1: 10,000$ & 2015 & \\
\hline & $1: 10,000$ & 2015 & Erlangen \\
\hline & $1: 10,000$ & 1969 & \multirow{2}{*}{ Nürnberg } \\
\hline & $1: 2000$ & 2006 & \\
\hline Soil map & $1: 25,000$ & 2015 & $\begin{array}{c}\text { Fürth, Schwabach, Erlangen, } \\
\text { Nürnberg }\end{array}$ \\
\hline Soil evaluation map & $1: 25000$ & 2001,2012 & $\begin{array}{c}\text { Fürth, Schwabach, Erlangen, } \\
\text { Nürnberg }\end{array}$ \\
\hline \multirow{5}{*}{ Topographic map } & $1: 25,000$ & $1966,1976,1987,1994$ & Fürth \\
\hline & $1: 25,000$ & $1969,1977,1988,2004$ & Schwabach \\
\hline & $1: 25,000$ & $1971,1983,1992,1997$ & Erlangen Nord \\
\hline & $1: 25,000$ & $1962,1982,1988,1993,1998$ & Erlangen Süd \\
\hline & $1: 25,000$ & $1962,1978,1987,1994,1998$ & Nürnberg \\
\hline Staticticol vearbole and & & 2014,2015 & Fürth \\
\hline statistics of the Bavarian & & 2015 & Schwabach \\
\hline State Office for statistics & & $2012,21013,2014,2015$ & Erlangen \\
\hline and data processing & & $1965,2013,2014,2015$ & Nürnberg \\
\hline
\end{tabular}

apparent distinction between the features. The process of visually interpreting digitally enhanced imagery attempts to optimize the complementary abilities of the human mind and the computer. The mind is excellent at interpreting spatial attributes on an image and is capable of identifying obscure or subtle features [15] [16]. Contrast stretching was applied on five Landsat scenes and five false color composites (FCC) were produced. These FCC were visually interpreted using on screen digitizing in order to delineate LC classes that could be easily interpreted such as built-up, green and open spaces. Some classes were spectrally confused (miss-classification) and could not be separated well by supervised classification. Hence, visual interpretation was required to separate them. Atmospheric correction were implemented in order to avoid the atmospheric influence. 


\subsection{Image Classification}

The LC classes are typically mapped from digital remotely sensed data through the process of a supervised digital image classification [16] [17] [18]. LULC classification through supervised classification method (training process), based on the field knowledge is employed to perform the classification. This classification method is used in many similar studies at different levels of LU planning classification of land cover to regional Level $1-2$ of the Anderson system and to spatial Level 2 - 3 of Anderson [2] [3] [4] [7] [19], and is well documented. It is a statistical method, which estimates the probability densities of the membership to the given pattern classes based on the values for each picture element (pixel) [3] [19]. In the current study, five major LULC classes were categorized: built-up (residential and commercial settlements, road), green and open areas, forest, agricultural land and water bodies. In order to increase the overall accuracy the LC mapping and ancillary data were integrated with the classification results. The classification results were spatially smoothed with the "majority-filter" $(3 \times$ 3 pixels). In this way, LULC were documented in the following years of 1972, 1985, 1998, 2003 and 2015. The changes were analyzed by overlay of the individual image classifications. For image processing ERDAS software10.1 and for GIS mapping and spatial analysis the software ESRI ArcMap 10.1 desktop were used.

\subsection{Data Analysis}

Three methods of data analysis are adopted in this study:

- Calculation of the area in hectares of the resulting LULC types for each year for each study area is based on Landsat-Classification.

The first task is to create a table showing the area of LULC classes in hectares and its percentage for each year (1972, 1985, 1998, 2003 and 2015) measured against each LULC type. The Percentage change was then calculated to determine the trend of change of each LU.

- Classification accuracy of each LULC class of used Landsat-images is then calculated using of reference maps and statistical data in order to evaluate the overall accuracy and then to determine the quality of information derived from the data of Landsat-Classification.

- The LULC statistics of both study areas are compared to assist in identifying the percentage change, trend, and rate of change of LULC in metropolitan areas.

\section{Results and Discussion}

\subsection{LULC Time Series Analysis of the Metropolitan City of Berlin}

Figure 2 depicts the LULC changes over the past 40 years. More than half of the metropolitan city of Berlin were occupied with the built-up class, mainly located in the center of the city. In the last 40 years, about $50 \%$ to $60 \%$ of the study area was dominated by built-up area. The built-up area has grown from 51\% in 1972 to $61 \%$ in the year of 2015 . Among the built-up areas, residential use has a very 

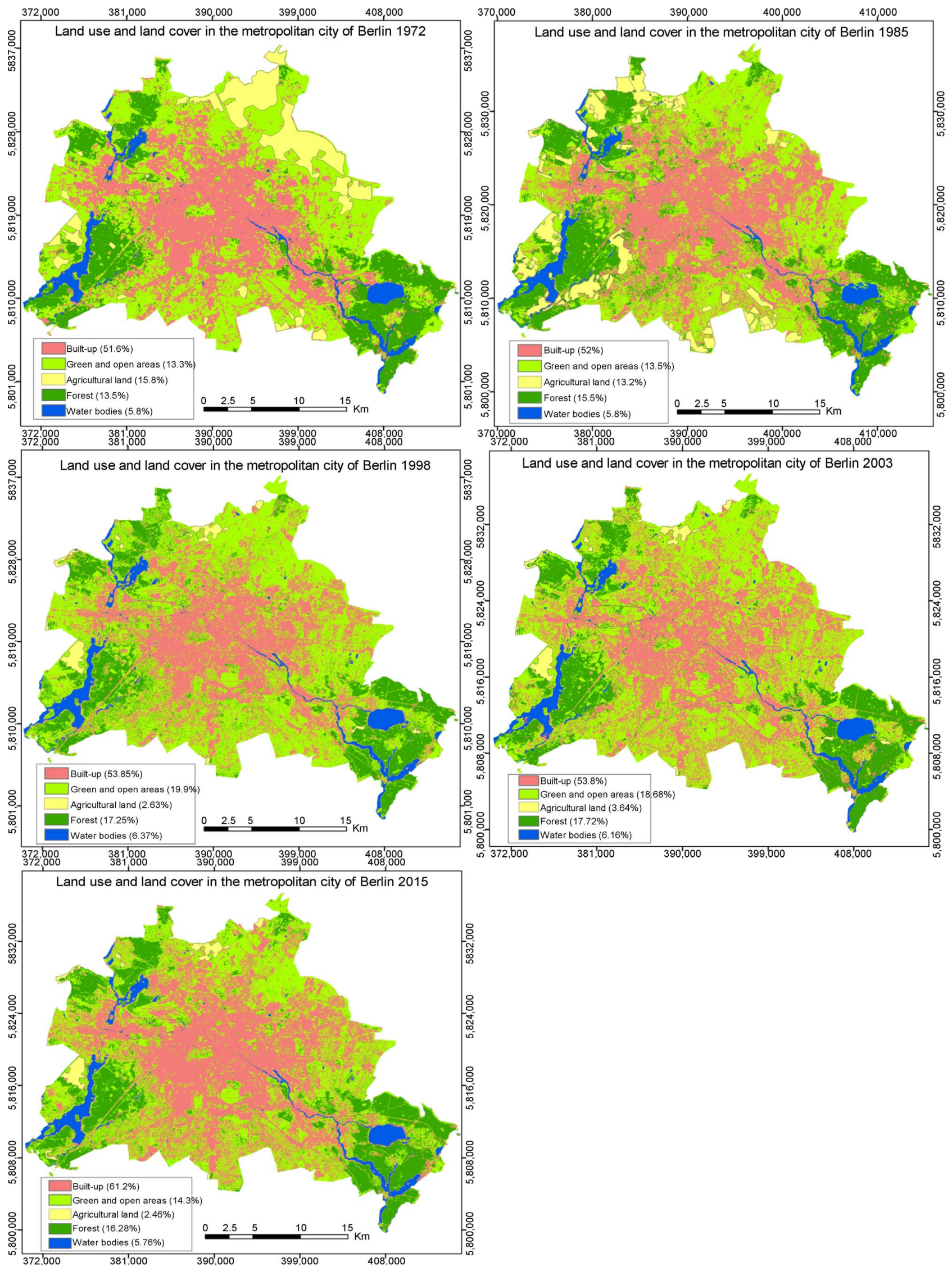

Figure 2. LULC change of the past 40 years in the metropolitan city of Berlin. 
high proportion. The residential use is followed by commercial and industrial use. In contracts, a large part of the suburban area was covered with green, open area, forest and agriculture showing the various types of non-built-up proportions as well as their distribution. Interestingly, green and open areas have been increased through the years. The amount was $13.3 \%$ in $1972,13.5 \%$ in 1985 , $19.9 \%$ in 1998, 18.38\% in 2003 and 14.3\% in 2015 (Table 4). Figure 3 and Table 4 shows that the agricultural areas were gradually converted into the forest areas in the last 40 years. The forest area showed an increase over the time, $13.5 \%$ in $1972,15.5 \%$ in $1985,17.25 \%$ in $1998,17.72 \%$ in 2003 and $16.28 \%$ in 2015 . In small areas, the farmland was converted into forest areas, particularly in the district of Pankow on one hand. However, on the other hand large forest areas such as the Grunewald and Düppel in the southwest, the Spandauer and Tegeler forest in the north-west and the large forest areas in the Köpenick district in the southeast of Berlin are tracking attention. Figure 3 and Table 4 show that the agricultural areas in 1972 were still covered relatively large even up to the edge of the city. As Table 4 shows, there is a decrease in the amount of agriculture: $15.8 \%$ in $1972,13.2 \%$ in $1985,2.63 \%$ in $1998,3.34 \%$ in 2003 and $2.46 \%$ in 2015. The increase in the area of settlements and traffic in the Berlin's area is mainly at the expense of the agricultural land.

Table 4. LULC change in the metropolitan city of Berlin.

\begin{tabular}{cccccccccccc}
\hline \multirow{2}{*}{ Class name } & \multicolumn{2}{c}{ 1972-August } & \multicolumn{2}{c}{ 1985-May } & \multicolumn{2}{c}{ 1998-April } & \multicolumn{2}{c}{ 2003-June } & \multicolumn{2}{c}{ 2015-May } \\
\cline { 2 - 11 } & ha & $\%$ & ha & $\%$ & ha & $\%$ & ha & $\%$ & ha & $\%$ \\
\hline Built-up & $45,956.84$ & 51.6 & $46,316.84$ & 52 & $47,953.26$ & 53.85 & $47,908.73$ & 53.8 & $54,498.41$ & 61.2 \\
Green and open areas & $11,845.46$ & 13.3 & $12,024.56$ & 13.5 & $17,720.89$ & 19.9 & $16,634.48$ & 18.68 & $12,734.11$ & 14.3 \\
Agricultural land & $14,072.06$ & 15.8 & $11,757.35$ & 13.2 & 2342.01 & 2.63 & 3241.41 & 3.64 & 2190.62 & 2.46 \\
Forest & $12,023.59$ & 13.5 & $13,805.98$ & 15.5 & $15,361.07$ & 17.25 & $15,779.61$ & 17.72 & $14,497.29$ & 16.28 \\
Water bodies & 5165.69 & 5.8 & 5166.11 & 5.8 & 5672.47 & 6.37 & 5485.46 & 6.16 & 5129.26 & 5.76 \\
Overall & $89,063.64$ & 100 & $89,063.64$ & 100 & $89,063.64$ & 100 & $89,063.64$ & 100 & $89,063.64$ & 100 \\
\hline
\end{tabular}

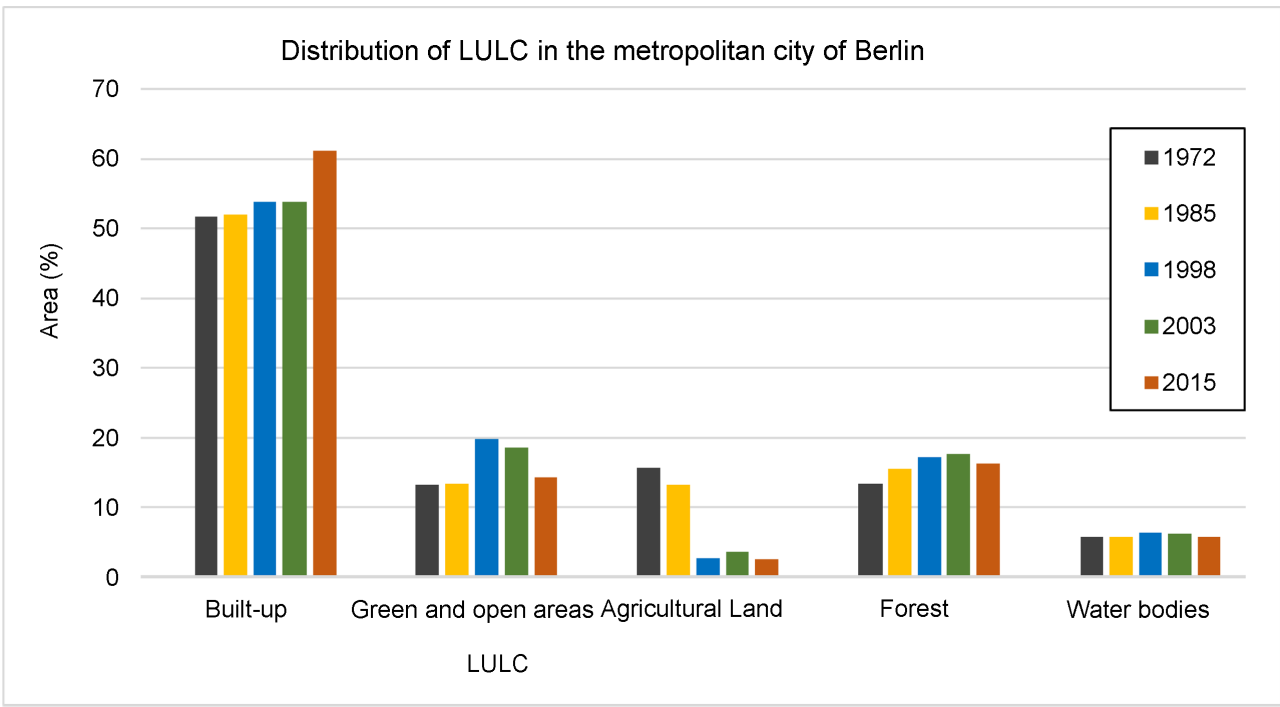

Figure 3. Distribution of LULC in the period of 1972-2015 in the metropolitan of Berlin. 
It is noteworthy that in the last 40 years almost $84.5 \%$ of the agricultural land has been converted into built up area, forest, green and open spaces. The proportion of agricultural land was reduced sharply between 1985 and 2015, compared to the previous period. This can be found in the outer city districts of Pankow, Marzahn-Hellersdorf and Lichtenberg. The agricultural areas, which cover $2.46 \%$ of the LU of the urban area in 2015, are now located in the northeastern of Berlin (Pankow and Weißensee). The water bodies contain lakes, rivers, canals and ponds. The proportion of water bodies was 5.8\% in 1972, 5.8\% in 1985, 6.37\% in 1998, 6.16\% in 2003 and $5.76 \%$ in 2015. The fluctuation of the mentioned percentages could be attributed to the rainfall and conversion of LU in the study area.

\subsection{Accuracy Assessment of the Metropolitan City of Berlin}

The estimation of classification accuracy is an integral part of the thematic evaluation of remote sensing data. Since the classification errors have influence on the accuracy of the change detection, the overall accuracy assessment must be considered. Additionally, the classification of the LULC and a reference map are compared with one another. In this regards, the basis of random raster samples [3] [20], or by overlay and intersection. This explains the importance of the integration of remote sensing and GIS in the detection of LULC changes. The current study used Environmental Atlas of Berlin to evaluate the overall accuracy assessment. These reference maps are real use of the built-up, green and open areas of two years of 2002 and 2015 (No. 06.01, 06.02, Edition 2002, No. 06.01, 06.02, Edition 2015). These reference maps were used to compared the Landsat classification of 2003 and 2015 to estimate the classification errors (Table 5). To derive the LULC classes the Producer's accuracies has been used. The Producer's accuracy decreases when more pixels of a respective class has not been recognized. This is so an error of exclusion. The one-to-one check of classification accuracy shows that the overall accuracy of classification is $87.8 \%$ for 2003 and $94 \%$ for 2015. A standard overall accuracy for LULC classification is known between 85 [4] and 90 percent [21]. Table 5 shows the details of single class accuracy for the years of 2003 and 2015.

Table 5 shows "built-up areas" as the most accurate Producer's accuracy for

Table 5. Accuracy statistics for the Landsat classification result for the years of 2003 and 2015.

\begin{tabular}{ccc}
\hline \multirow{2}{*}{ Class name } & \multicolumn{2}{c}{ Producer's accuracy (\%) } \\
\cline { 2 - 3 } & 2003 & 2015 \\
\hline Built-up & 97 & 93 \\
Green and open areas & 81 & 93 \\
Agricultural land & 75 & 97 \\
Forest & 98 & 94 \\
Water bodies & 88 & 95 \\
Overall & 87.8 & 94 \\
\hline
\end{tabular}


both years of 2003 and 2015. Whereas, the lowest classification accuracy is for the class "agricultural land" for the year 2003. This could be explained by the fact that this class is spectrally confused with the "green and free areas". In addition, the temporal difference between the Landsat classified image 2003 and the reference map of 2002 could be the reason to this cause. The accuracy for the same class in 2015 was $97 \%$. This is probably due to the integration of the visual interpretation of LU map (2015) with the Landsat classified image (2015). The information obtained from the topographic map could be an addition to previous ones. Table 6 shows the accuracy assessment comparison between the Landsat LULC classification with the LU of the environmental Atlas of Berlin for the years of 2003 and 2015 in both in hectare and percentages.

\subsection{LULC Time Series Analysis of the Metropolitan Region of Nürnberg-Fürth-Erlangen-Schwabach}

The built-up area has been the dominant LU between the years of 1972 to 2015. This amount increased from $44.65 \%$ to $44.69 \%$ between the years of 1972 to 1988, a slight decrease between the years of 1998 and 2003 and then an increase from $42.61 \%$ to $51.49 \%$ in the years of 2003 to 2015 . The expenses of increase of built-up area were on the shoulders of green and open area as well forested area, especially in the largest cities of Nürnberg and Erlangen. Around $40 \%$ to 50\% of the area in the region was unoccupied by settlements and traffic during the investigation period. These were predominantly agricultural areas or forest areas, which were found in the outskirts of the region. Larger connected farmland were found in the western part of Fürth and in the western Northwestern part of the city of Erlangen. Figure 4, Figure 5 and Table 7 shows that the agricultural areas has covered a relative large area and remained stable within the duration on this study. Agricultural area were $23.58 \%$ in $1972,22.06 \%$ in $1985,21.19 \%$ in $1988,20.61 \%$ in 2003 and $19.26 \%$ in 2015 . The loss of agricultural land was mainly due to the development of residential, commercial and transport areas in the region within the study period. In contrast, forested areas have had the least effect on agricultural loss. The region has about $15 \%$ of its area covered by forest. The largest forested area are located in the region of Erlangen and Nürnberg.

Table 6. Comparing the accuracy assessment of Landsat LULC classification with the LU of environmental Atlas of Berlin.

\begin{tabular}{ccccccccc}
\hline \multirow{2}{*}{$\begin{array}{c}\text { Class name } \\
\text { Landsat } 2003\end{array}$} & \multicolumn{2}{c}{$\begin{array}{c}\text { Environmental } \\
\text { Atlas } 2002\end{array}$} & Landsat 2015 & $\begin{array}{c}\text { Environmental } \\
\text { Atlas 2015 }\end{array}$ \\
\cline { 2 - 10 } & ha & $\%$ & ha & $\%$ & ha & $\%$ & ha & $\%$ \\
\hline Built-up & $47,908.73$ & 53.8 & $49,024.85$ & 55.00 & $54,498.41$ & 61.20 & 52,325 & 58.74 \\
Green and open areas & $16,634.48$ & 18.68 & $13,504.12$ & 15.15 & $12,734.11$ & 14.30 & 13,686 & 15.36 \\
Agricultural land & 3241.41 & 3.64 & 4323.10 & 4.85 & 2190.62 & 2.46 & 2251 & 2.52 \\
Forest & $15,779.61$ & 17.72 & $16,044.50$ & 18.00 & $14,497.29$ & 16.28 & 15,437 & 17.32 \\
Water bodies & 5485.46 & 6.16 & 6239.53 & 7.00 & 5129.26 & 5.76 & 5397 & 6.06 \\
Overall & $89,063.64$ & 100 & $89,136.10$ & 100 & $89,063.64$ & 100 & 89,096 & 100 \\
\hline
\end{tabular}


They spread out to the outskirts as well. The forest areas had almost $20 \%$ of the area in 1972. Nevertheless, the forested areas were largely reduced due to the settlement development in the last decades. Figure 4, Figure 5 and Table 7 show the mentioned changes in details. One could note that the forested area were significantly reduces from 2003 to 2015 in comparison with the previous periods. The forest areas which comprised 19.01\% of the region in 1972, decreased to $17.76 \%$ in 1998 and to $15.14 \%$ in 2003 . Then this area remains almost stable at
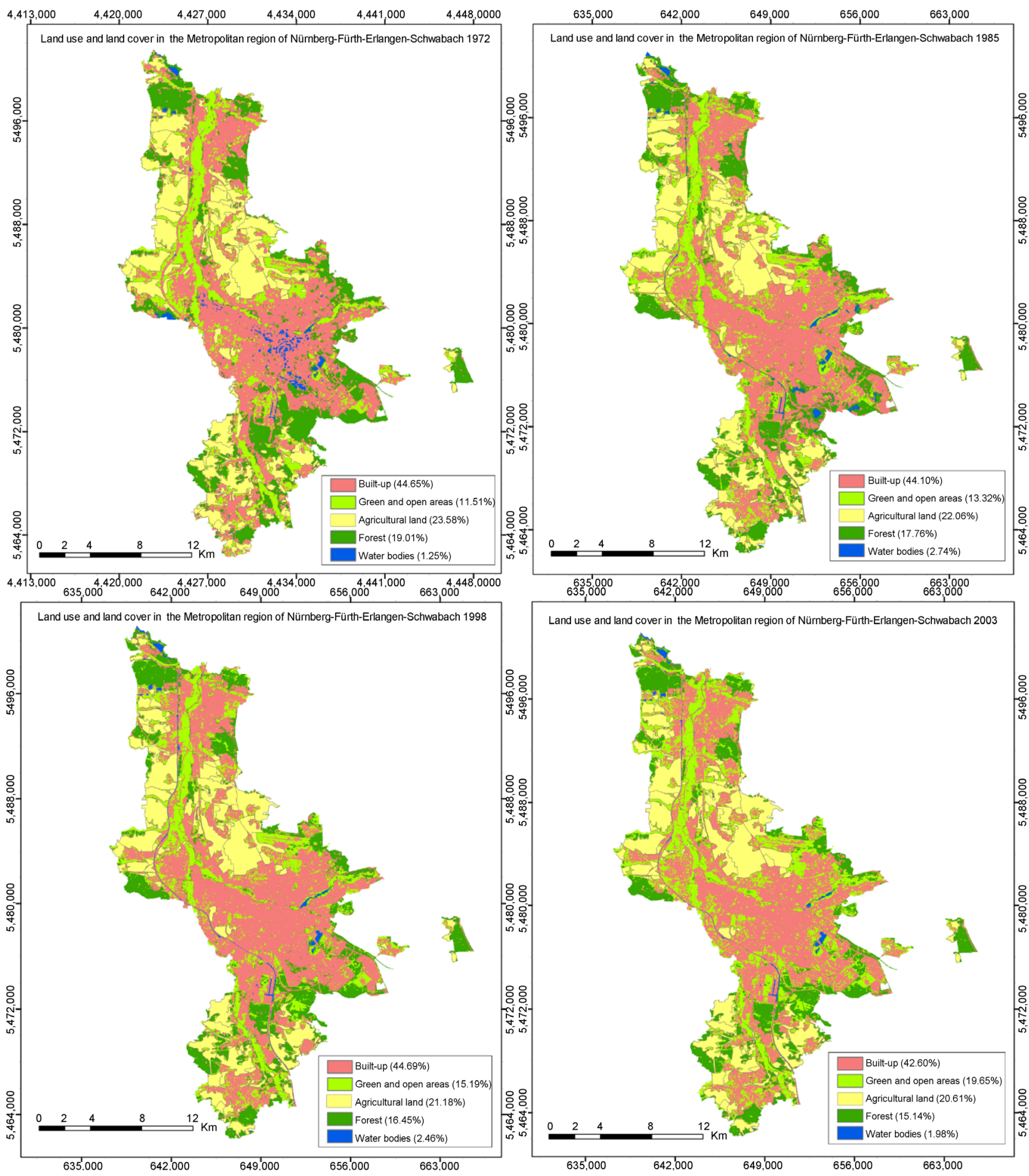


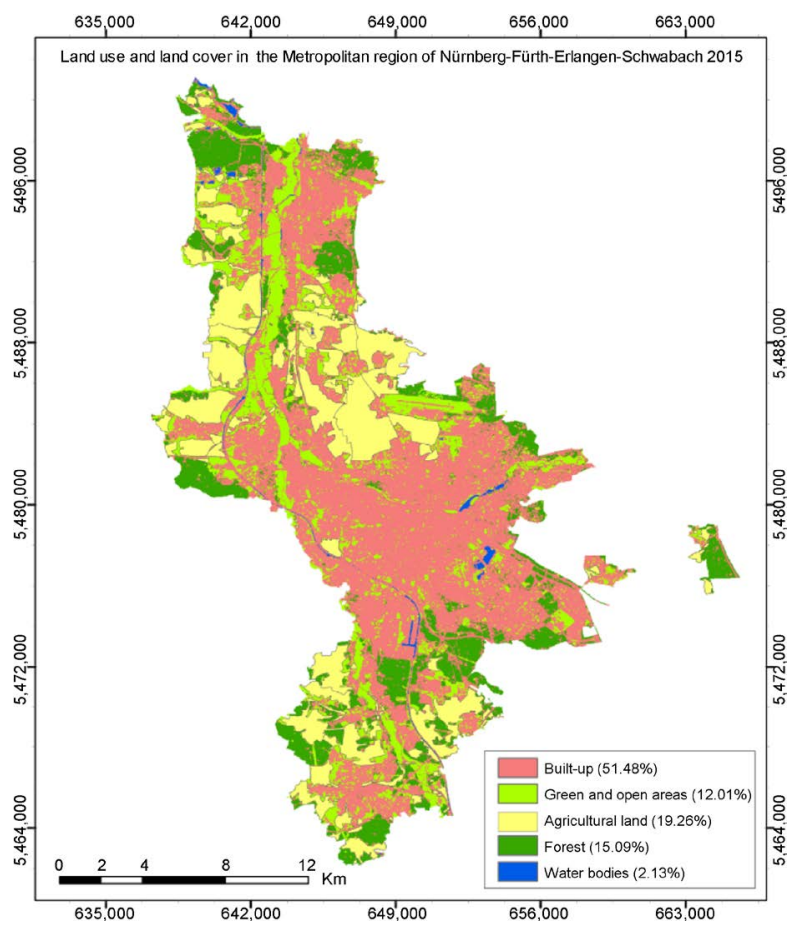

Figure 4. Distribution of LULC in the period of 1972-2015 in the metropolitan region of Nürnberg-Fürth-Erlangen-Schwabach.

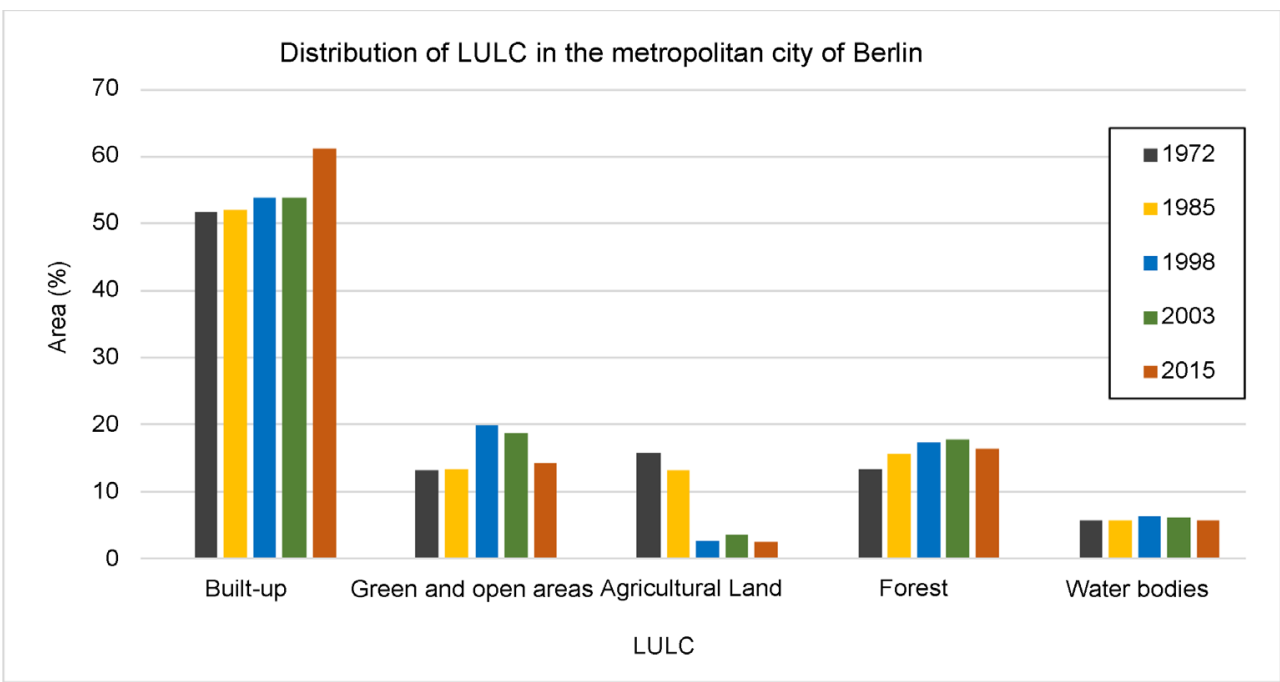

Figure 5. Distribution of LULC in the period 1972-2015 in the study area region of Nürnberg-FürthErlangen-Schwabach.

Table 7. LULC classes of the metropolitan region of Nürnberg-Fürth-Erlangen-Schwabach.

\begin{tabular}{ccccccccccc}
\hline \multirow{2}{*}{ Class name } & \multicolumn{2}{c}{ 1972-August } & \multicolumn{2}{c}{ 1985-May } & \multicolumn{2}{c}{ 1998-April } & \multicolumn{2}{c}{ 2003-June } & \multicolumn{2}{c}{ 2015-May } \\
\cline { 2 - 11 } & ha & $\%$ & ha & $\%$ & ha & $\%$ & ha & $\%$ & ha & $\%$ \\
\hline Built-up & $16,429.68$ & 44.65 & $16,226.29$ & 44.10 & $16,439.17$ & 44.69 & $15,672.24$ & 42.61 & $18,938.8851 .49$ \\
Green and open areas & 4235.04 & 11.51 & 4902.66 & 13.32 & 5590.89 & 15.10 & 7227.97 & 19.65 & 4419.72 & 12.01 \\
Agricultural land & 8677.80 & 23.58 & 8116.74 & 22.06 & 7794.00 & 21.19 & 7581.42 & 20.61 & 7086.42 & 19.26 \\
Forest & 6994.08 & 19.01 & 6537.33 & 17.77 & 6051.06 & 16.45 & 5569.65 & 15.14 & 5553.45 & 15.10 \\
Water bodies & 461.52 & 1.25 & 1009.35 & 2.74 & 907.25 & 2.46 & 731.09 & 1.99 & 784.00 & 2.13 \\
Overall & $36,798.12$ & 100 & $36,792.37$ & 100 & $36,782.37$ & 100 & $36,782.37$ & 100 & $36,782.47$ & 100 \\
\hline
\end{tabular}


$15.19 \%$ during the years of 2003 to 2015. Results (Figure 4, Figure 5 and Table 7) show that the forested area in the Northwestern and eastern part of Erlangen as well as the Southern part of Nürnberg has been converted into the green area and built-up area. The green and open areas covers about $11.51 \%$ of the total area of the region in $1972,13.32 \%$ in $1985,15.10 \%$ in $1998,19.65 \%$ in 2003 and $12.01 \%$ in 2015 .

With the adoption of the Landscape Protection Area Ordinance in $28^{\text {th }}$ June 2000 , many of open areas located at the protected area were preserved. Thus, the open areas were significantly expanded on one hand. However, on the other hand there is a clear decline in the green area. The decrease in the proportion of green areas could be attributed to the following factors: extend in cemeteries, realization of sports grounds and conversion of children's playgrounds into built-up areas. It is expected that according to the published reports, the region is experiencing a significant expansion of green areas from 2014 onward. The transformed areas of the region-such as the areas that are located in the city of Nürnberg-currently offer the largest development and construction rates within the green and open area in the inner city. The proportion of the water surface shows a relatively large change in the investigation area. These proportions of water surface were $1.25 \%$ in $1972,2.74 \%$ in $1985,2.46 \%$ in $1998,1.99 \%$ in 2003 and $2.13 \%$ in 2015 . These changes of water surface could be attributed to changes the rainfall, the conversion of the LU and the ecological change of the several lakes and ponds in the western urban area. Last but not least, the consumption of land in the region, i.e. the conversion of agricultural and forestry land but also natural areas (uncultivated areas) into the settlement and traffic area, essentially results from the use of land for construction activities.

\subsection{Accuracy Assessment of the Metropolitan Region of Nürnberg-Fürth-Erlangen-Schwabach}

To improve the overall accuracy of Landsat image classification of the study area, the LU reference map of 2015 (edition 2015, scale 1:10,000) has been used. The reference map were derived from the official land register information system and are available from the Bavarian Agency for Surveying and Geoinformation (ALKIS). In addition, "Bavarian state office for statistics and data processing" provided this research with the LU statistical data for the year of 2015. These data were used to improve the overall accuracy assessment of the study area. However, the statistical data for three classes of agriculture, forest and water bodies has been provided. Nevertheless, the results were used to compare to estimate the classification errors and the quality of the 2015 Landsat image classification. Table 8 shows the accuracy assessment of each LULC class. The one-to-one check of classification accuracy shows an overall accuracy of $87.4 \%$ for the year of 2015. A standard overall accuracy for LULC classification is known to be between 85 [4] and 90 percent [21].

The LU accuracy assessment based on the statistical data for the three mentioned classes are as the following: Agricultural land $77.53 \%$, forest $81.18 \%$ and 
water bodies $98.9 \%$. The overall accuracy assessment for these three classes were $85.87 \%$. Table 8 shows water bodies to be as the most accurate LU class with 98.8\% accuracy. Agricultural land has the least accuracy of $89.65 \%$. Confused spectral class with green and open area. Table 9 illustrates the LULC accuracy assessments in both hectare and percentage.

\section{Conclusions}

In this study, the Landsat archive images were used to detect the history of LULC changes in the metropolitan city of Berlin and the metropolitan region of Erlangen-Nürnberg-Fürth-Schwabach. In addition, the historical data from the maps and the statistical data have been used to check the accuracy of this detection.

Built-up area proved to occupy the largest space in both study area in the period of current study. The percentages of the built-up area were $51 \%$ to $61 \%$ for the metropolitan city of Berlin and $45 \%$ to $52 \%$ for the metropolitan region of Erlangen-Nürnberg-Fürth-Schwabach during the past 40 years. A dramatic change has been seen from agriculture to built-up, green and open as well as forested area, especially within the period of 1985 to 2015 in Berlin. Until 2015, the agricultural area occupied a relatively large part, but remained stable, of the metropolitan region of Erlangen-Nürnburg-Fürth-Schwabach. There was an increase in forested and green and open area from the period of 1972 to 2003 for both study area on one hand. On the other hand, from 2003 to 2015 there is a dramatic change from forested and green and open land into other LU covers, in

Table 8. LULC accuracy of the Nürnberg-Fürth-Erlangen-Schwabach area for the year of 2015.

\begin{tabular}{cc}
\hline Class name & Producer's accuracy (\%) \\
\hline Built-up & 82.20 \\
Green and open areas & 94.74 \\
Agricultural land & 79.65 \\
Forest & 81.48 \\
Water bodies & 98.80 \\
Overall & 87.4 \\
\hline
\end{tabular}

Table 9. Comparing the accuracy assessment of Landsat LULC classification with the LU of ALKIS for the metropolitan region of Nürnberg-Fürth-Erlangen-Schwabach.

\begin{tabular}{ccccc}
\hline Class name & \multicolumn{2}{c}{ Landsat 2015} & \multicolumn{2}{c}{ ALKIS 2015 } \\
\cline { 2 - 5 } & ha & $\%$ & ha & $\%$ \\
\hline Built-up (settlement, road) & $18,938.88$ & 51.49 & $16,062.153$ & 43.71 \\
Green and open areas & 4419.72 & 12.01 & 4194.882 & 11.45 \\
Agricultural land & 7086.42 & 19.26 & 8887.808 & 24.18 \\
Forest & 5553.45 & 15.10 & 6808.435 & 18.51 \\
Water bodies & 784 & 2.13 & 792.722 & 2.15 \\
Overall & $36,782.47$ & 100 & 36746 & 100 \\
\hline
\end{tabular}


particular the built-up area in both study areas. In the last decade, the open area in the two areas of study has been significantly expanded to ensure the nature and soil balance and for the recuperation under protection. The increase in forest and green areas is an inviting trend in the two study areas to preserve the natural ecosystems and its biological diversity in the urban areas of these regions.

The results show that the overall accuracy of remote sensing data is between $88 \%$ and $94 \%$ for Berlin and from $86 \%$ to $87.5 \%$ for Erlangen-Nürnburg-FürthSchwabach. This could indicate that integrating remotely sensed and GIS data are useful to monitor and mapping the LULC for both urban areas. However, better spatial and temporal resolution data enables us with improved results to avoid environmental and ecological problems.

\section{Acknowledgements}

This research was supported and funded by the Alexander von Humboldt Foundation. The work was carried out at the Department of Geomorphology and Soil Geography at the Geographical Institute at the Humboldt-Universität Berlin.

\section{References}

[1] Prakasam, C. (2010) LU and LC Change Detection through Remote Sensing Approach: A Case Study of Kodaikanal Taluk, Tamil Nadu. http://www.ipublishing.co.in/jggsvol1no22010.html

[2] Stefanov, W.L., Ramsey, M.S. and Christensen, P.R. (2001) Monitoring Urban LC Change: An Expert System Approach to LC Classification of Semiarid to Arid Urban Centers. Remote Sensing of Environment, 77, 173-185.

[3] Yildirim, H., Özel, M.E., Radberger, R. and Akça, A. (2002) Monitoring von Landnutzungsänderungen über einen langen Zeitraum mit Hilfe von Satellitenfernerkundung und GIS. Allgemeine Forst und Jagdzeitung, 173, 15-20.

[4] Anderson, J.R., Hardy, E.E., Roach, J.T. and Witmer, R.E. (1976) A LU and LC Classification System for Use with Remote Sensor Data. http://www.pbcgis.com/data_basics/anderson.pdf

[5] Wu, J., Vincent, B., Yang, J., Bouarfa, S. and Vidal, A. (2008) Remote Sensing Monitoring of Changes in Soil Salinity: A Case Study in Inner Mongolia, China. Sensors, 8, 7035-7049. https://doi.org/10.3390/s8117035

[6] Foody, G.M. (2000) Estimation of Sub-Pixel LC Composition in the Presence of Untrained Classes. Computers \& Geosciences, 26, 469-478.

[7] Ridd, M.K. (1995) Exploring a V-I-S (Vegetation-Impervious Surface-Soil) Model for Urban Ecosystem Analysis through Remote Sensing: Comparative Anatomy for Cities. International Journal of Remote Sensing, 16, 2165-2185. https://doi.org/10.1080/01431169508954549

[8] Cibula, W.G. and Nyquist, M.O. (1987) Use of Topographic and Climatological Models in a Geographical Data Base to Improve Landsat MSS Classification for Olympic National Park. Photogrammetric Engineering and Remote Sensing, 53, 6775 .

[9] Franklin, S.E. (1994) Discrimination of Subalpine Forest Species and Canopy Density Using Digital CASI, SPOT PLA and Landsat TM Data. Photogrammetric Engineering and Remote Sensing, 60, 1233-1241. 
[10] Harris, P.M. and Ventura, S.J. (1995) The Integration of Geographic Data with Remotely Sensed Imagery to Improve Classification in an Urban Area. Photogrammetric Engineering and Remote Sensing, 61, 993-998.

[11] Vogelmann, J.E., Sohl, T. and Howard, S.M. (1998) Regional Characterization of LC Using Multiple Sources of Data. Photogrammetric Engineering and Remote Sensing, 64, 45-57.

[12] Greenberg, J.D. and Bradly, G.A. (1997) Analyzing the Urban-Wildland Interface with GIS: Two Case Studies. Journal of Forestry, 95, 18-22.

[13] Stuckens, J., Coppin, P.R. and Bauer, M.E. (200) Integrating Contextual Information with Per-Pixel Classification for Improved LC Classification. Remote Sensing of Environment, 71, 282-296.

[14] Beyer, W., Krappweis, S., Maciuga, T., Räder, J. and Sinz, M. (2002) Nationalatlas Bundesrepublik Deutschland-Dörfer und Städte, die Metropolregion Berlin-Brandenburg, Band 5, Spektrum-Akademischer Vlg, Heidelberg, 166-167.

[15] Lillesand, T.M. and Kiefer, R.W. (2015) Remote Sensing and Image Interpretation. 7th Edition, Wiley, New York.

[16] Shalaby, A. and Tateishi, R. (2007) Remote Sensing and GIS for Mapping and Monitoring LC and Land-Use Changes in the Northwestern Coastal Zone of Egypt. Applied Geography, 27, 28-41.

[17] Campbell, J.B. and Wynne, J.H. (2011) Introduction to Remote Sensing. 5th Edition, The Guilford Press, New York.

[18] Thomas, I.L., Benning, V.M. and Ching, N.P. (1987) Classification of Remotely Sensed Images. Geocarto International, 2, 77-77. https://doi.org/10.1080/10106048709354113

[19] Foody, G.M., Campbell, N.A., Trood, N.M. and Wood, T.F. (1992) Derivation and Application of Probabilistic Measures of Class Membership from the MaximumLikelihood Classification. Photogrammetric Engineering and Remote Sensing, 58, 1335-1341.

[20] Congalton, R.G. (1991) A Review of Assessing the Accuracy of Classifications of Remotely Sensed Data. Remote Sensing of Environment, 37, 35-46.

[21] Lins, K.S. and Kleckner, R.L. (1996) LC Mapping: An Overview and History of the Concepts. In: Scott, J.M., Tear, T.H. and Davis, W.F., Eds., Gap Analysis: A Landscape Approach to Biodiversity Planning, American Society for Photogrammetry and Remote Sensing, Bethesda, MD, 57-65. 
Submit or recommend next manuscript to SCIRP and we will provide best service for you:

Accepting pre-submission inquiries through Email, Facebook, LinkedIn, Twitter, etc. A wide selection of journals (inclusive of 9 subjects, more than 200 journals)

Providing 24-hour high-quality service

User-friendly online submission system

Fair and swift peer-review system

Efficient typesetting and proofreading procedure

Display of the result of downloads and visits, as well as the number of cited articles Maximum dissemination of your research work

Submit your manuscript at: http://papersubmission.scirp.org/

Or contact nr@scirp.org 